\title{
SIMULATION OF THE IMPACT OF HIGHER HARMONICS ON THE TRANSIENT PROCESS OF INDUCTION MACHINE FED FROM PWM INVERTERS
}

\author{
Nenad Marković, Slobodan Bjelić, Jeroslav Živanić, Uroš Jakšić
}

Preliminary communication

In this paper a fundamental mathematical model (algorithm) for determination of condition of induction machine as well as the simulation procedure for measurement of certain values in program MATLAB has been presented. A scheme of measuring system and results of simulation application are presented on output lists. Thus, measuring system gradually develops and improves as combination of information and results of previous steps in modeling with new elements essential for development of researches when induction machine is fed through $P W M$ inverter.

Keywords: algorithm; induction machine; inverter; measurement; simulation

Simuliranje utjecaja viših harmonika na prijelazni proces indukcionog stroja napajanog iz PWM invertera

Prethodno priopćenje

U radu je prikazan osnovni matematički model (algoritam) za određivanje stanja indukcionog stroja kao i postupak simulacije mjerenja pojedinih vrijednosti u programu MATLAB. Na izlaznim listama prikazana je shema mjernog sustava i rezultati primjene simulacije. Na taj način se mjerni sustav postupno razvija i usavršava kao kombinacija informacija i rezultata prethodnih koraka u modeliranju s novim elementima značajnim za razvoj dijagnostičkog sustava kada se indukcioni stroj napaja pomoću $P W M$ invertera.

Ključne riječi: algoritam; dijagnostika; indukcioni stroj; mjerenje; simulacija

\section{Introduction}

In polyphase and multiple-winding induction machines in the air gap, beside fundamental harmonics also occur many harmonics with frequency that is lower and higher than the fundamental-network frequency, and have one name- higher harmonics. They are characterized by time and space distribution in the induction machine $[1,2]$. Time-dependent harmonics reach the gap of stator and rotor of the induction machine from the machine derivatives (connections toward electric network, from mechanical connector such as shaft and from thermal derivatives) and space-dependent harmonics occur due to constructive particularities and non-linearity of the parameters in the machine; this assumption is also valid for model of double-pole induction machine $(p=1)[3,4]$.

The first source of higher time harmonics in a steadystate regime is non-sinusoidal voltage on derivatives of induction machine. If symmetric and non-sinusoidal voltages also associate to idealized induction machine the value of magnetic induction in air gap shall have the form of associated voltage, which besides the fundamental also contains the higher harmonics. By knowing the given voltage form on derivatives of induction machine it is possible to calculate and measure or simulate the spectral composition of the fields in the gap.

The second source of higher time harmonics in air gap is an engine shaft-mechanical derivative of the induction machine. During the changing of loading moment $M_{o p}$ or during the changing of speed of rotation $n$ (frequency) the higher harmonics occur in the air gap. On the side of mechanical derivative higher harmonics in air gap can also occur during non-linear change of rotation $n$ (frequency) and during simultaneous non-linear change of moment $M_{o p}$ and speed of rotation $n$ (frequency) [5].

Time-dependent higher harmonics can also reach the air gap through thermal derivatives-from areas that surround conducting parts of the induction machine. In the case of non-linear changes of the temperature in the induction machine environment higher time-dependent harmonics occur and shape of magnetic field becomes deformed. The highest values of higher harmonics amplitudes occur at thermal shocks $[4,6]$.

Space dependent harmonics occur due to specific construction and have big influence on energy transformation process in induction machine. Important space harmonics of an induction machine are [5]: fundamental harmonic of magnetic excitation force $(M E F)$ and $M E F$ teeth and harmonics occurred due to non-linearity of electric machine parameters, and technological harmonics occurred due to application of combined frequencies (in modern induction machines). Important influence on space harmonics spectra has eccentricity of rotor and stator axes, conical or ellipsoidal shape of rotor and deformities in winding positioning of stator and rotor $[1,5]$.

That means that in air gap exists the spectrum of field which can be divided on sets of harmonics, and division should be performed according to time and space origin.

\section{Measurement of significant quantities of the induction machine}

Previously mentioned division of higher harmonics on time-dependent and space-dependent can be only considered conditionally because all harmonics are connected to the energy of a field in the gap and can be considered only together in the space and time, Fig. 1.

Process equations in induction machines present mathematical model (algorithm of theoretically idealized machine) for the analysis of magnetic field in the gap between rotor and stator and calculation (measurement/simulation) of spectrum of voltages and currents harmonics of induction machine that gives the picture on its condition. 


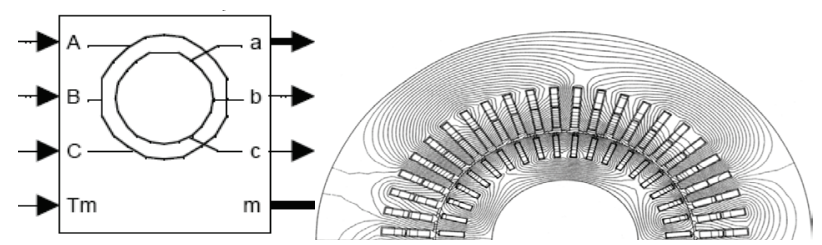

Figure 1 Scheme [7] and distribution of fields of double-pole three-phase machine of induction engine 3,4 MW. One flux line presents unit value $0,005 \mathrm{~Wb} / \mathrm{m} \mathrm{[5]}$

All modern numerical methods presently used by engineers for calculation of distribution of magnetic fields in the gap start from the method of final differences or from method of finite elements and defined initial conditions and come to calculation of inductivity and reactance as inductive parameters of the induction machine [7].

The aim of this paper is the simulation procedure of measurement of certain values on the model of threephase ideal double-pole induction machine with smooth rotor and air gap; all parameters are linear and voltage on derivatives is rectangular with $P W M$ inverter $[7,8]$. Induction machine has 3 windings on stator with number of coils $N_{A} N_{\mathrm{B}} N_{C}$ and three windings on rotor with number of coils $N_{a} N_{\mathrm{b}} N_{c}$

For three-phase induction machine in space system of phase coordinates $A, B, C, a, b, c$ differential equations for contours where phase voltages are present are as follows:

$$
\begin{aligned}
& V_{A}=R_{A} i_{A}+\frac{\mathrm{d} \psi_{A}}{\mathrm{~d} t} \\
& V_{B}=R_{B} i_{B}+\frac{\mathrm{d} \psi_{B}}{\mathrm{~d} t}, \\
& V_{C}=R_{C} i_{C}+\frac{d \psi_{C}}{\mathrm{~d} t} \\
& V_{a}=R_{a} i_{a}+\frac{\mathrm{d} \psi_{a}}{\mathrm{~d} t} \\
& V_{b}=R_{b} i_{b}+\frac{\mathrm{d} \psi_{b}}{\mathrm{~d} t} . \\
& V_{c}=R_{c} i_{c}+\frac{\mathrm{d} \psi_{c}}{\mathrm{~d} t}
\end{aligned}
$$

The values of mechanical quantities are:

$$
\begin{aligned}
& \frac{\mathrm{d} \omega_{r}}{\mathrm{~d} t}=\frac{p}{J}\left(T_{e}-F \omega_{m}-T_{m}\right) \Rightarrow \\
& \Rightarrow J \frac{\mathrm{d} \omega_{r}}{\mathrm{~d} t}=J \frac{2 \pi}{60} \frac{\Delta n}{\Delta t}=p\left(T_{e}-F \omega_{m}-T_{m}\right)
\end{aligned}
$$

where $V$ voltages $A, B, C, a, b, c ; i_{i}$ rotor currents $i_{r}$ and stator currents $i_{s} ; R_{s}, R_{r}$ active resistances of stator and rotor; $\psi_{i}$ the resultant magnetic fluxes; $\omega_{r}$ electrical angular velocity $\left(\omega_{r} \mathrm{x} p\right) ; \omega_{m}$ angular velocity of the rotor; $p$ number of poles induction machines; $T_{e}$ electromagnetic torque induction machine; $T_{m}$ shaft mechanical torque induction machine; $F$ combined rotor and load viscous friction coefficient; $J$ combined rotor and load inertia coefficient.

The resultant flux in phase $A$ can be determined from the relation:

$$
\begin{gathered}
\psi_{A}=L_{A} i_{A}+M_{A B} i_{B}+M_{A C} i_{C}+M_{A a} i_{a}+ \\
+M_{A b} i_{b}+M_{A c} i_{c} \\
\psi_{a}=L_{a} i_{a}+M_{a B} i_{B}+M_{a C} i_{C}+M_{A a} i_{A}+ \\
+M_{a b} i_{b}+M_{a c} i_{c}
\end{gathered}
$$

In the similar way relations for resultant fluxes of other 5 contours which relates to phases $B, C, a, b, c$ are written. In the real inductivity coordinates and mutual inductivity in relations given for fluxes are coefficients with periodical values, which change as functions of harmonic at rotation of induction machine rotor [3, 7].

If expressions for fluxes in Eq. (4) and (5) are included in Eq. (1), (2) and (3), solutions with a few dozen elements and periodically variable coefficients will be obtained. In order to avoid these periodical coefficients, mathematical transition-transformation to another appropriate system of coordinates is necessary where in the air gap the field is rotating and can be presented by resultant vector of rotating field $B_{o b}$. By projecting of resultant vector of rotor currents, voltage, and flux on certain axes (here on $d, q, 0$ stator axes), expressions that correspond to matrices of transitional values can be determined [7, 9].

\section{Matrix of transformation from $0 d q$ components to uvw components and inverse matrix of reverse process of transformation from uvw to $0 d q$}

System matrix $0 d q$ (Park's transformation matrix) corresponds best to induction machines construction because it takes into account inequality of impedances on longitudinal and transverse axis and therefore is used in analysis of transitional processes in electric machines [2]. Transition matrix from $0 d q$ components into $u v w$ components and inverse matrix related to inverse process of transition from $u v w$ into $0 d q$ are defined by Eq. (6) and (7) $[10 \div 13]$ :

$\left[T_{0 d q \rightarrow u v w}\right]=\left[T_{u v w}\right]\left[T_{0 d q}\right]^{-1}$,
$\left[T_{u v w \rightarrow 0 d q}\right]=\left[T_{0 d q \rightarrow u v w}\right]^{T}$.

Measuring system of diagnostics of technical condition of induction machine based on the analysis of space and time dependent harmonics of magnetic field must contain sensors for conversion of parameters of space and time harmonics into unique electrical signal. With the assistance of $A D$ converter obtained information is entered into computer for further processing [14, 15]. Today, PC is mostly used for additional processing and rarely special controller with appropriate software support.

Possible scheme with computer support can be performed in two ways, Fig. 2, through:

1. Simple analysis, measurement and recording of higher harmonics of voltage and stator currents.

2. Calculation of coefficients of mathematical model (this procedure is applicable only for basic harmonics [9, 16]). 


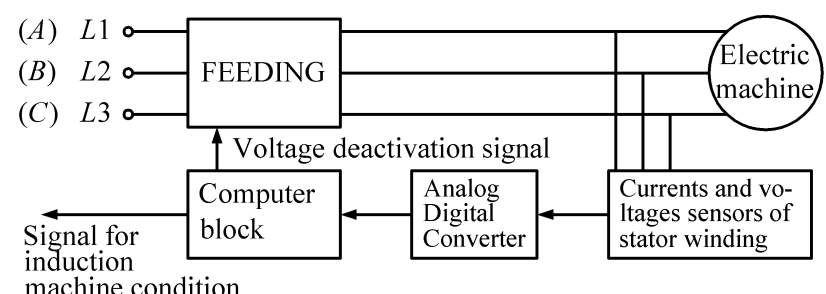

Figure 2Basic scheme for diagnostic system

According to the first way, the task comes down to program writing or to usage of one of the programs for simulation of induction machine in an open-loop speed control on a 3,6 kW, $230 \mathrm{~V}$ industrial motor (MATHLAB/Simulink, program Mathematica Wolfram etc.) [5].

The program memory must contain composition of harmonics at normal induction machine condition and at engine running periodically to record results and compare composition of harmonics regarding the normal engine. A command for signalling at elevated vibrations or for disconnection of the engine from the drive at higher disturbances must be given to the program.

Realization of the first way for writing of a certain program is not difficult, but procedure itself has some faults. Primarily, it is necessary to establish correlation between defects of mechanical parts with parameters that determine harmonics, and requires a huge amount of computation when a large number of harmonics should be retained. On the other hand, this procedure does not allow the identification of defects. The second way shows that calculation of coefficients of mathematical model requires the complex programs, since coefficients are calculated in the real time and must be compared with values obtained in the operating process of induction engine.

As discussed the complexity of the second way is reflected in writing of mathematical model that contains differential equations for each harmonic respectively, where massive system of equations, very difficult for solving, is obtained. Regardless of applied way, 1 or 2 , in both cases a program which performs analysis of higher harmonics of stator voltages and currents is needed. Program which refers to spectral analysis must rely on signals obtained from sensors that contain parameters of harmonics components, and data about them shall be used in additional analysis of mathematical model.

\section{Simulation of dynamic operation regime of the induction machine fed by rectangular voltage}

The induction machine block operates in any state: as generator or engine. The operation mode is dictated by the sign of the mechanical torque (positive for engines, negative for generators). The electrical part of the induction machine is represented as the four-poles and the mechanical part as a second-order system. Electrical variables are brought to the stator. This is indicated by (') sign in the equations given below. All stator and rotor quantities are in the arbitrary two-axis reference frame $(d q$ frame). The subscripts used are defined as follows, Fig. 3:

Subscript definition: $d$ : axis quantity $d ; q$ axis quantity $q ; r$ rotor quantity; $s$ : stator quantity; $L$ : leakage inductance; $m$ magnetizing inductance.

Applying Eq. (1) $\div(7)$ the following is obtained:

$$
\begin{aligned}
& V_{q s}=R_{s} i_{q s}+\frac{\mathrm{d}}{\mathrm{d} t} \varphi_{q s}+\omega \varphi_{d s}, \\
& \varphi_{q s}=L_{s} i_{q s}+L_{m} i_{q r}^{\prime}, \\
& V_{d s}=R_{s} i_{d s}+\frac{\mathrm{d}}{\mathrm{d} t} \varphi_{d s}-\omega \varphi_{d s}, \\
& \varphi_{d s}=L_{s} i_{d s}+L_{m} i_{d r}^{\prime}, \\
& V_{q r}^{\prime}=R_{r}^{\prime} i_{q r}^{\prime}+\frac{\mathrm{d}}{\mathrm{d} t} \varphi_{q r}^{\prime}+\left(\omega-\omega_{r}\right) \varphi_{d r}^{\prime}, \\
& \varphi_{q r}^{\prime}=L_{r}^{\prime} i_{q r}^{\prime}+L_{m} i_{q s}, \\
& V_{d r}^{\prime}=R_{r}^{\prime} i_{d r}^{\prime}+\frac{\mathrm{d}}{\mathrm{d} t} \varphi_{d r}^{\prime}+\left(\omega-\omega_{r}\right) \varphi_{q r}^{\prime}, \\
& \varphi_{d r}^{\prime}=L_{r}^{\prime} i_{d r}^{\prime}+L_{m} i_{d s}, \\
& T_{e}=\frac{3}{2} \cdot p\left(\varphi_{d s} i_{q s}-\varphi_{q s} i_{d s}\right), \\
& L_{s}=L_{l s}+L_{m}, \\
& L_{r}^{\prime}=L_{l r}^{\prime}+L_{m} .
\end{aligned}
$$
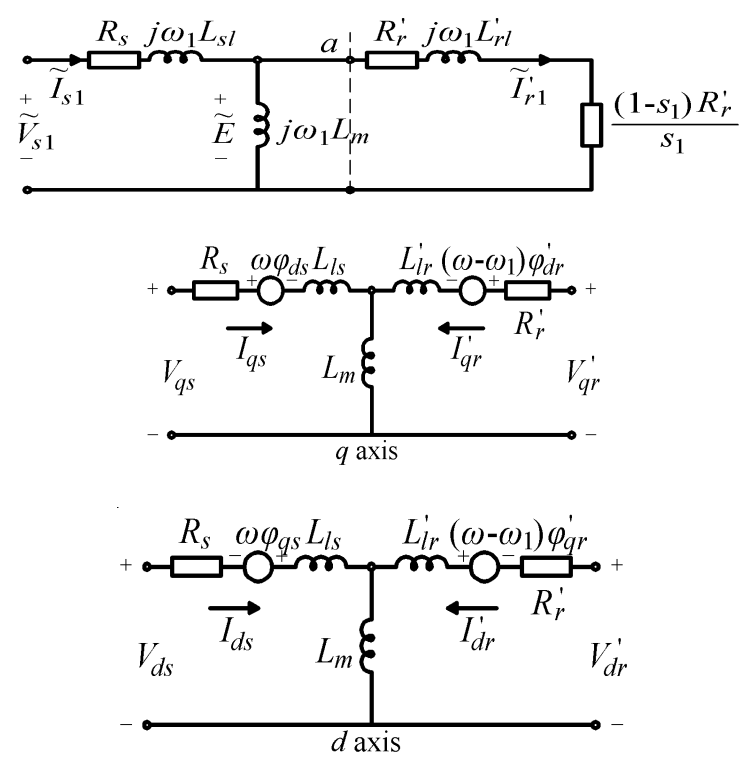

Figure 3 Equivalent electric schemes and development on $d$-axis and $q$-axis

Mechanical system of quantities is:

$$
\begin{aligned}
& \frac{\mathrm{d}}{\mathrm{d} t} \omega_{m}=\frac{1}{2 H}\left(T_{e}-F \omega_{m}-T_{m}\right), \\
& \frac{\mathrm{d}}{\mathrm{d} t} \theta_{m}=\omega_{m} .
\end{aligned}
$$

Parameters of induction machine block are defined as follows; all quantities are referred to the stator.

Definition of parameters is: $R_{s}, L_{i s}$ stator resistance and leakage inductance; $R_{r}^{\prime}, L_{i r}^{\prime}$ rotor resistance and leakage inductance; $L_{m}$ magnetizing inductance; $R_{s}, L_{r}^{\prime}$ total stator and rotor inductances; $V_{q s}, i_{q s} q$ axis stator voltage and current; $V_{q r}^{\prime}, i_{q r}^{\prime} q$ axis rotor voltage and current; $V_{d s}, i_{d s} d$ axis stator voltage and current; $V_{d s}^{\prime}, i_{d s}^{\prime} d$ axis rotor voltage and current; $\varphi_{q s}, \varphi_{d s}$ stator $q$ and $d$ axis; $\varphi_{q r}^{\prime}, \varphi_{d r}^{\prime}$ rotor $q$ and $d$ axis; $\theta_{m}$ number of pole pairs; $\theta_{r}$ electrical rotor angular position $\left(\theta_{r} \times p\right) ; H$ combined rotor and load inertia constant. 


\section{Simulation of mathematical model of operation of induction machine}

The software MATLAB Simulink Power System model [7] is used for simulation of mathematical model of operation of induction machine, scheme in Fig. 4, which uses value equations. Behaviour of three-phase induction machine, as loading in dynamic operation regime has been tested at three-phase induction engine start-up, with nominal value of $3,6 \mathrm{~kW}$ fed by inverter that gives rectangular voltage form $[17 \div 20]$. At the engine start-up fed from inverter converter it is typical that spectrum of harmonics of engine current continuously changes during the whole start-up interval $[2,21]$.
For obtaining of more authentic responses at the output (stator and rotor currents, speed of rotation and moment) the following parameters of induction machine have been selected:

Parameters induction machine:

Rotor type: Wound

Reference frame: Stationary

Nom. power, $L-L$, voltage and frequency: $\left[P_{n}=3 \times 1200(\mathrm{VA}), V_{n}=230(\mathrm{Vrms}), f_{n}=50(\mathrm{~Hz})\right]$

Stator: $\left[R_{s}=0,435(\Omega), L_{i s}=2 \times 2,0 \mathrm{e}-03(\mathrm{H})\right]$

Rotor: $\left[R_{r}^{\prime}=0,816(\Omega), L_{i r}^{\prime}=2,0 \mathrm{e}-03(\mathrm{H})\right]$-values referred to stator

Mutual inductance: $L_{m}=69,31 \mathrm{e}-03(\mathrm{H})$

Inertia, friction factor, pairs of poles $\left[J=0,089\left(\mathrm{kgm}^{2}\right)\right.$, $F=0$ (N.m.s), $p=2]$.

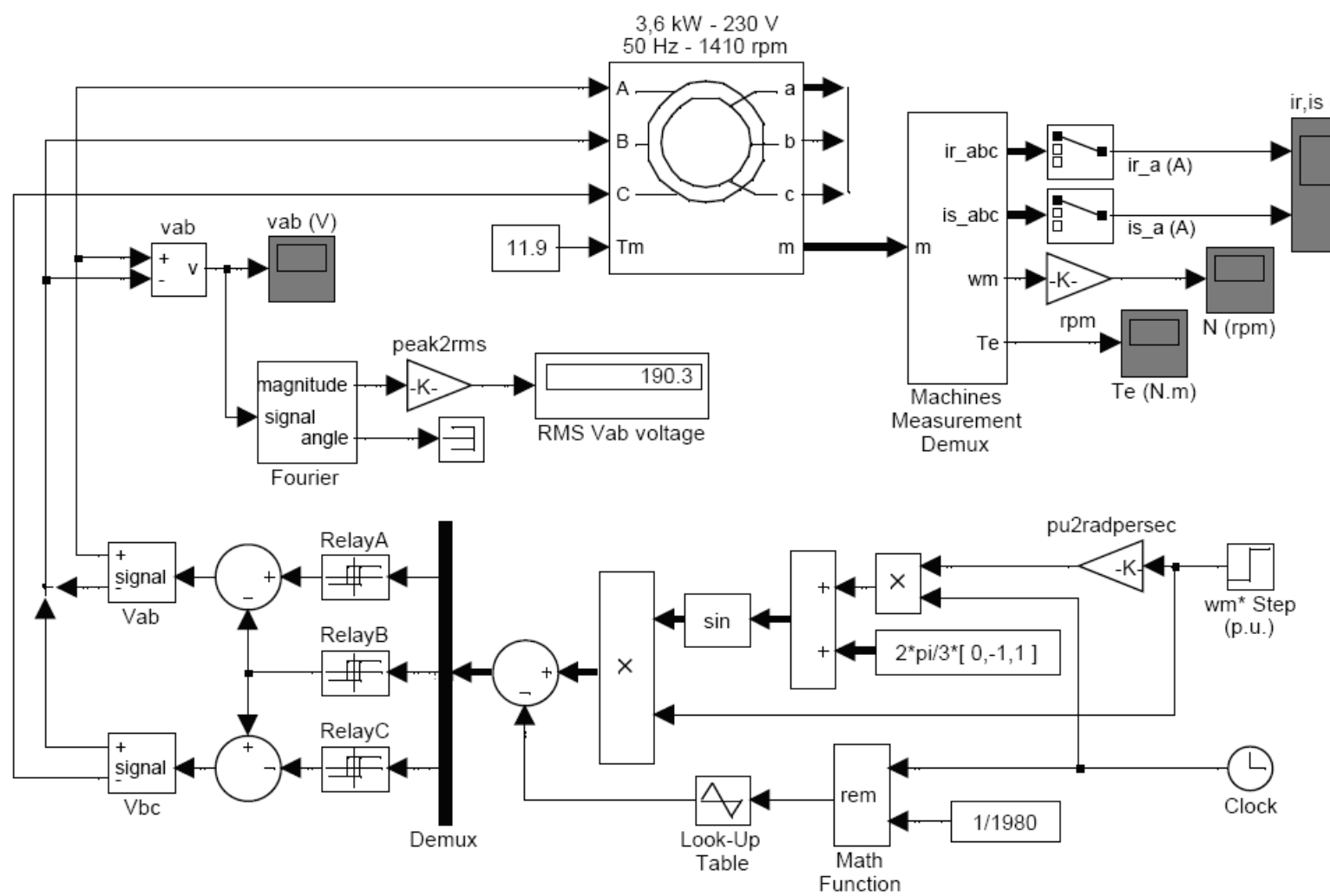

Figure 4 Induction machine fed through $P W M$ inverter. Inverter with impulse width modulation-impulse range modulation. Low-voltage three-phase induction engine $3,6 \mathrm{~kW}$ "Sever"-JUS ISO 9001 (source: www.sever.rs) $n=1410 \mathrm{~min}^{-} 1$, Protection IP 54 , Voltage $230 \mathrm{~V}, f=50 \mathrm{~Hz}$

\section{Simulation results}

Time forms of voltage harmonics $V_{a b}\left(1,3\right.$, and $\left.5^{\text {th }}\right)$ (rectangular impulses of same amplitude, which, at the same time, present values of magnetic induction in the gap of stator and rotor) are presented in Fig. 5.

Fig. 6 represents appropriate spectrum of current harmonics for stator and rotor of simulated $3^{\text {rd }}$ and $5^{\text {th }}$ harmonic.

Fig. 7 represents harmonics spectrums of stator and rotor torque during the starting of induction machine and the impacts of simulated $3^{\text {rd }}$ and $5^{\text {th }}$ harmonics, while Fig. 8 represents time forms of speed of rotation of stator and rotor and the impacts of the $3^{\text {rd }}$ and $5^{\text {th }}$ harmonic coming into inverter for feeding and operation of the machine.

For $1^{\text {st }}$ basic and $3^{\text {rd }}$ and $5^{\text {th }}$ harmonic the same time forms of currents, rotation speed and moment are obtained. By comparing time forms of spectrum of voltage harmonics at the induction machine input obtained from $P W M$ inverter and currents of rotor and stator it can be seen that induction machine manifests certain insensitivity to higher harmonics elements. Such insensitivity could be due to imperfection of the model for simulation or mathematical procedure regarding dual transformation-transition process from $u v w$ (in this case phase $a, b, c)$ into $0 d q$ components or due to inverter operation.

Deviation of current time form from sine form can be noticed during the run-up interval. According to Fig. 5 it can be concluded that values of voltage amplitude are the same for all harmonics of voltage and the value of magnetic induction $V$ in air gap has the form of impressed voltage. 

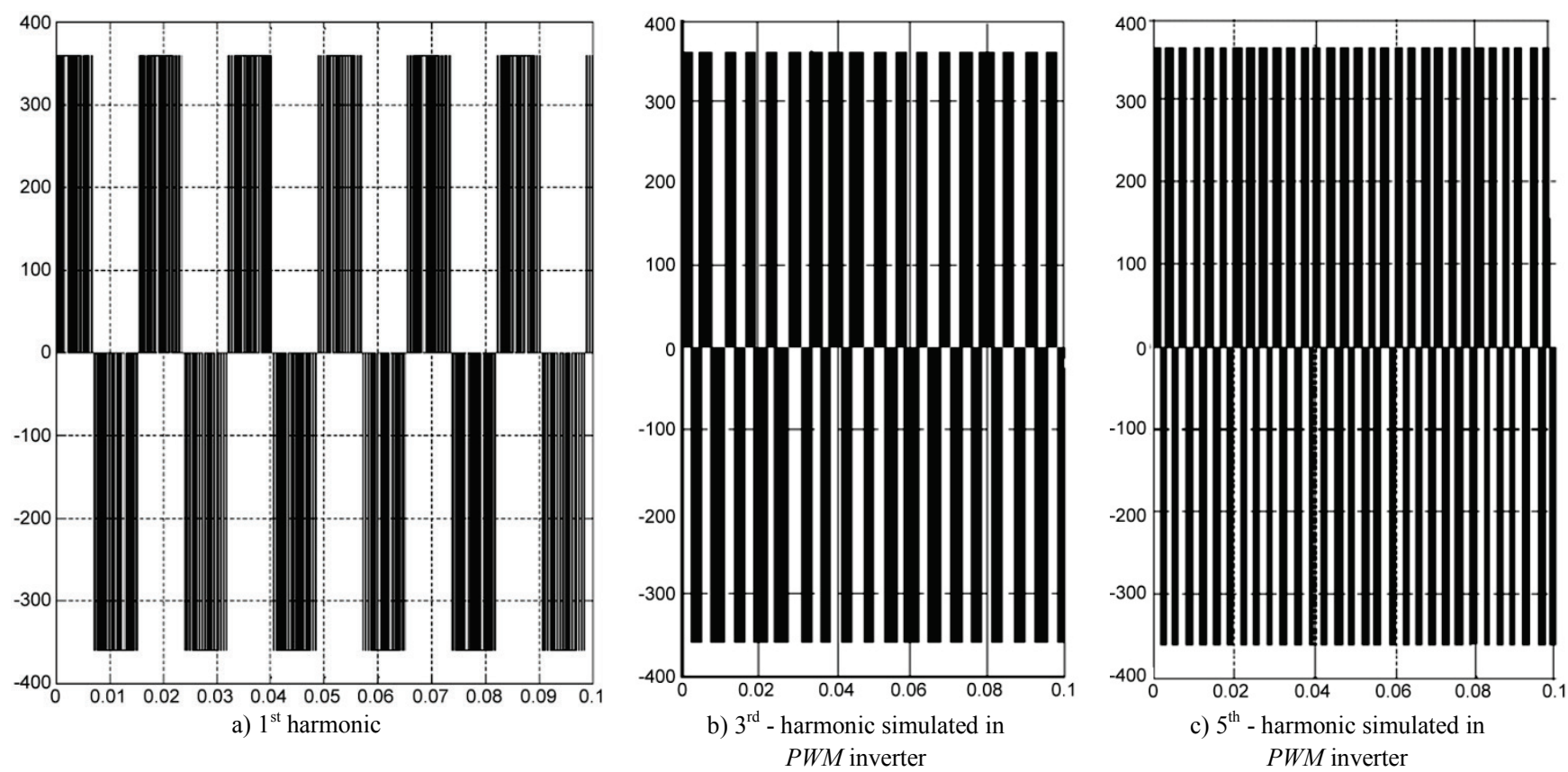

Figure 5 Interphase rectangular voltage $V_{a b}$ from $P W M$ inverter at the induction machine input
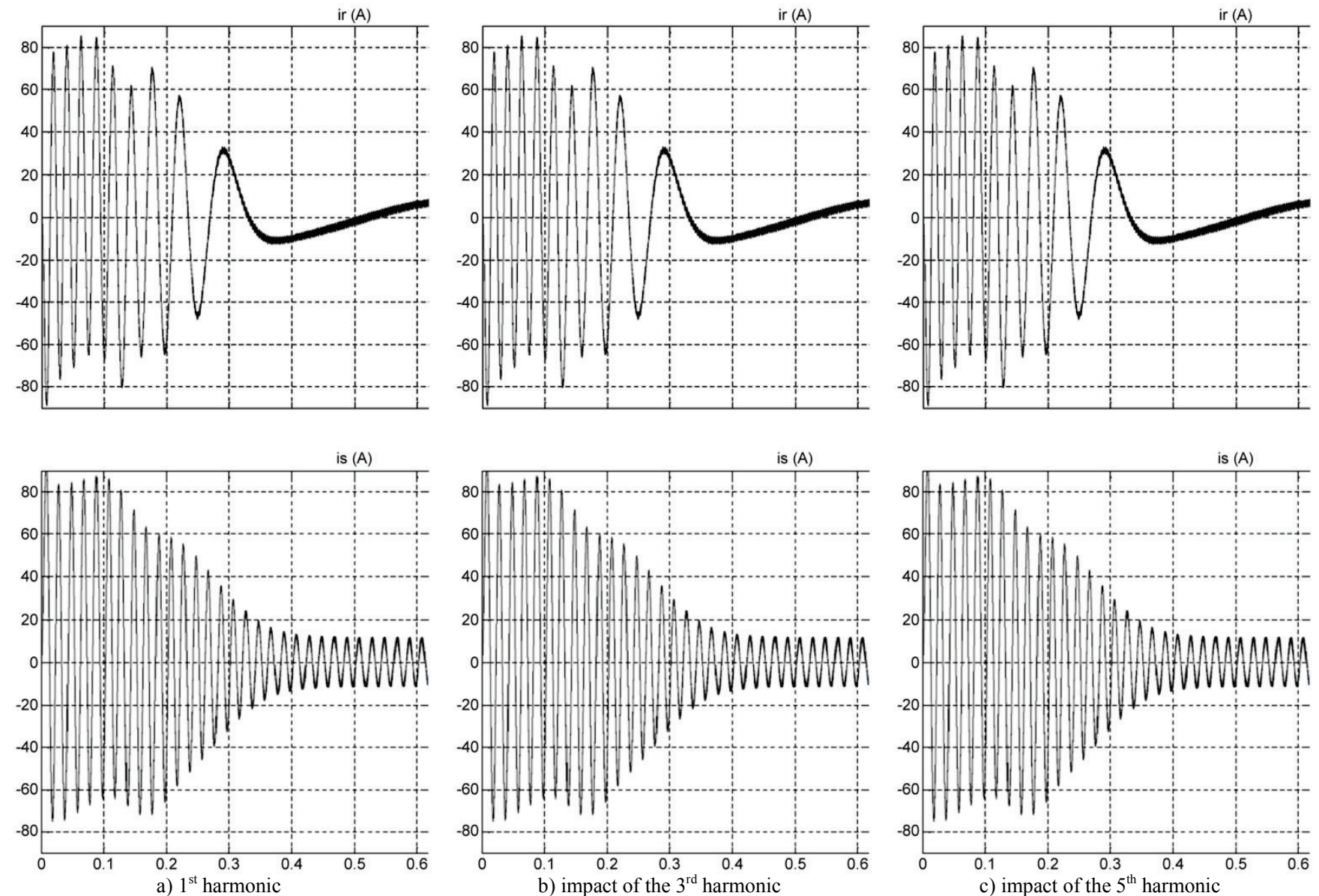

Figure 6 Harmonic spectrum of stator and rotor currents of induction machine and impacts of simulated $3^{\text {rd }}$ and $5^{\text {th }}$ harmonic coming to inverter for feeding and operation of the machine 


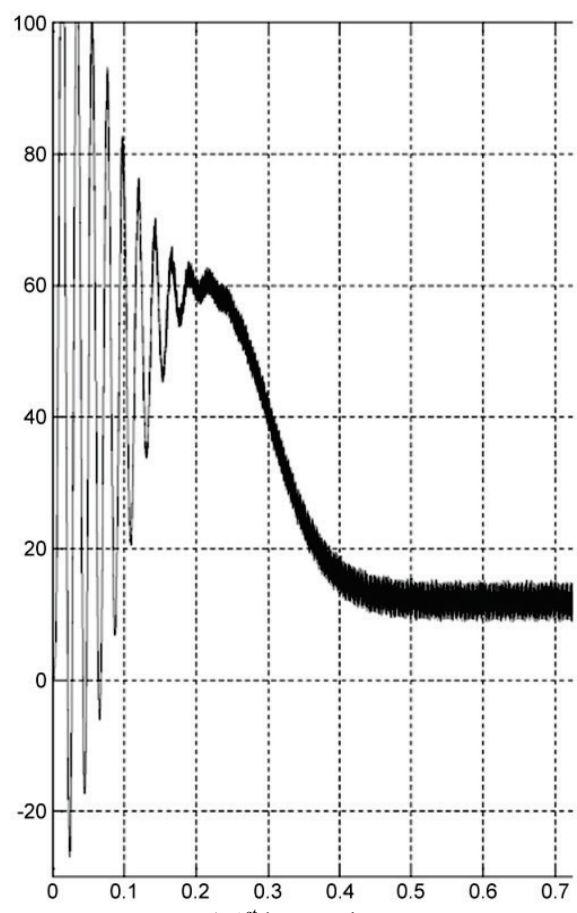

a) $1^{\text {st }}$ harmonic

Figure 7 Harmonic spectrum of stator and rotor torque of the induction machine and the impacts of simulated $3^{\text {rd }}$ and $5^{\text {th }}$ harmonic coming to inverter for feeding and operation of the machine

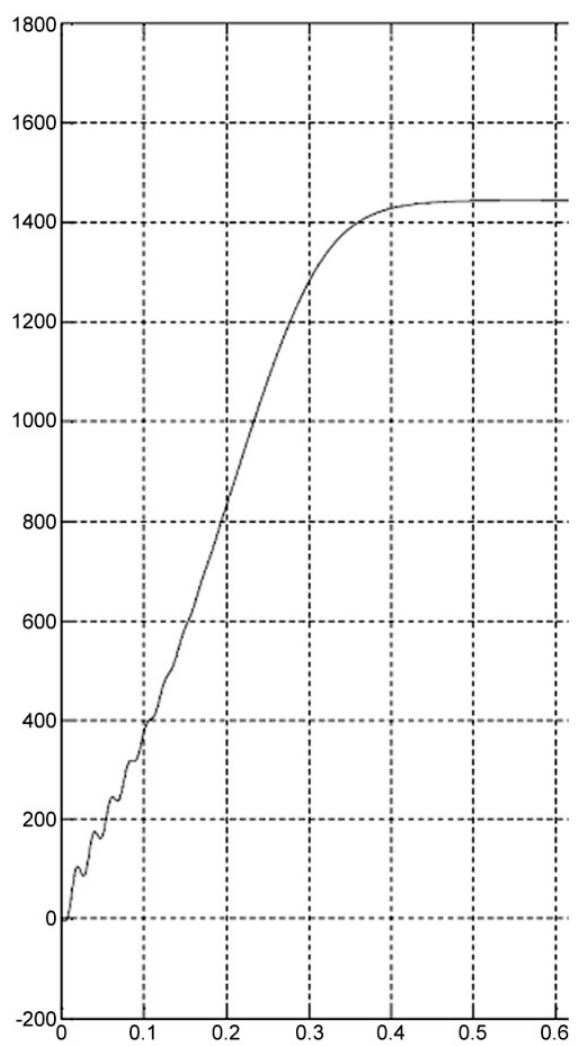

a) $1^{\text {st }}$ harmonic

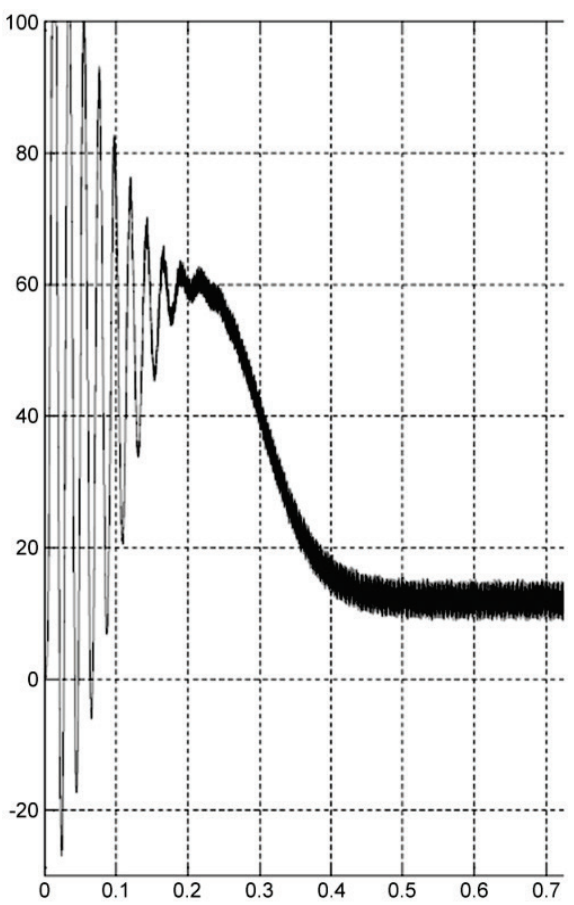

b) impact of the

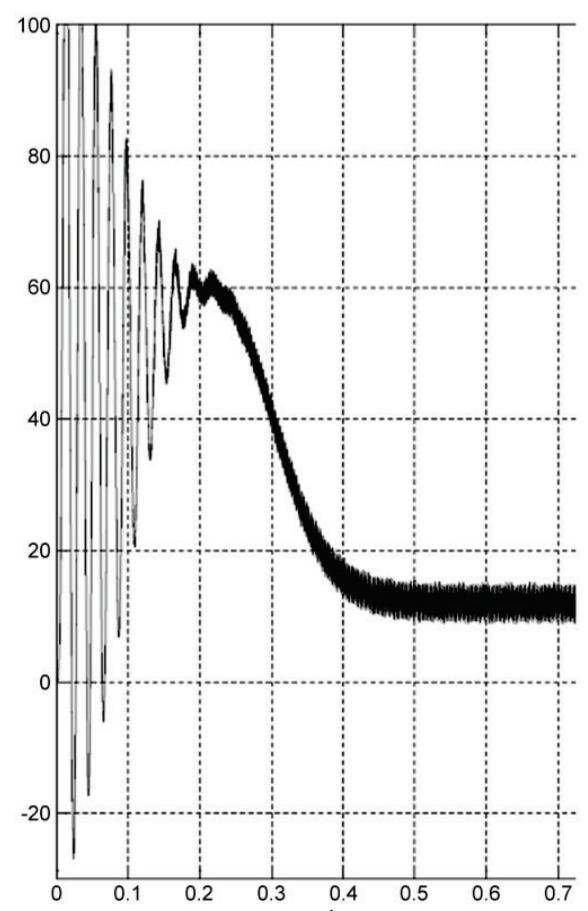

c) impact of the $5^{\text {th }}$ harmonic 0.7

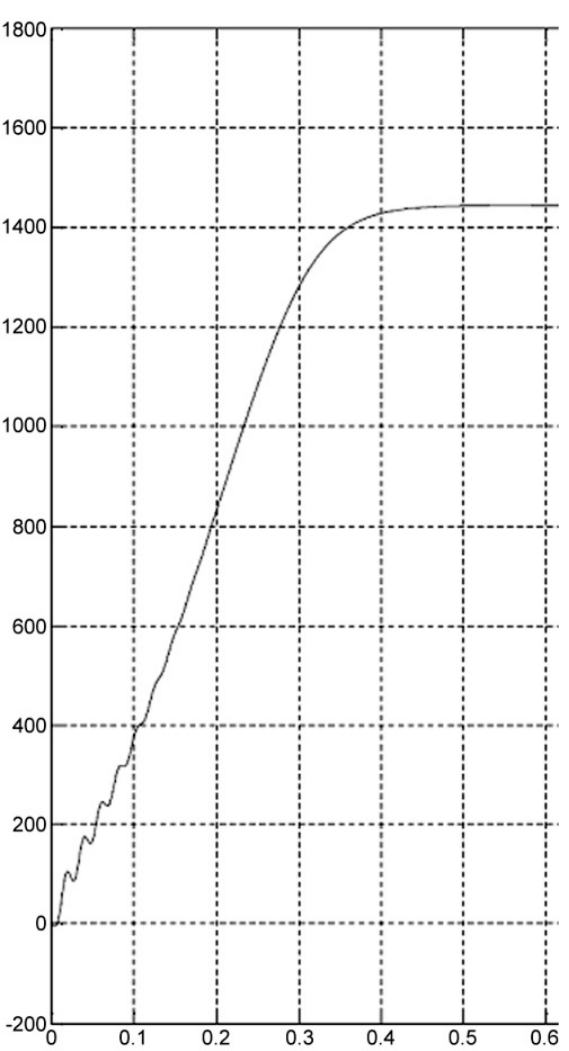

b) impact of the $3^{\text {rd }}$ harmonic

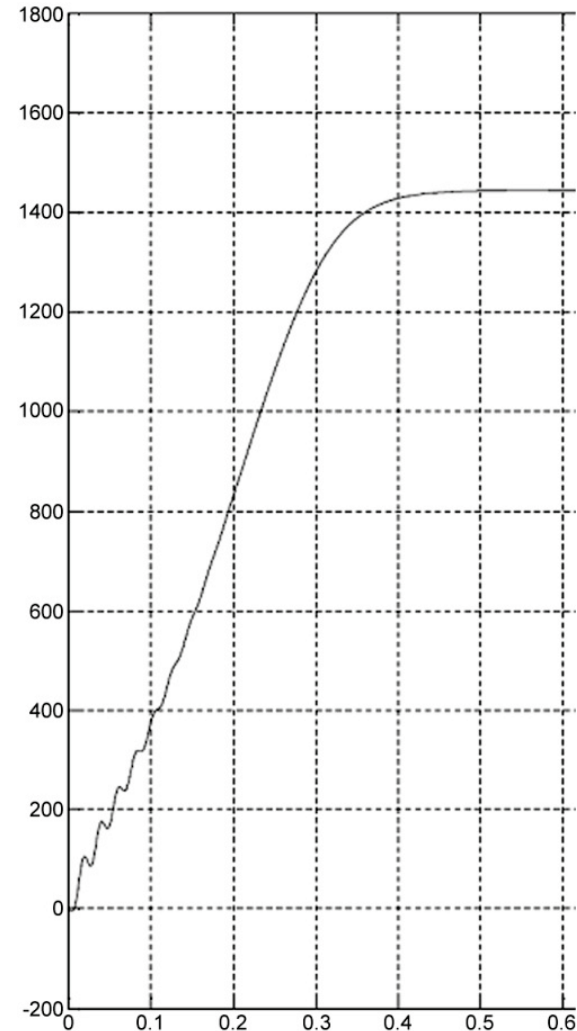

c) impact of the $5^{\text {th }}$ harmonic coming to inverter for feeding and operation of the machine

\section{Conclusion}

For the purpose of presentation of testing results, a simulation model of three-phase active power filter with referent current with dynamic model of a three-phase induction machine.

Simulation of feeding of induction machine by rectangular voltage harmonics in all electrical and mechanical time variable quantities is created: stator and rotor currents, rotation speed and electromagnetic moment.

Simulation and analysis of time forms-diagrams of voltages, stator and rotor currents, speed of rotation, electromagnetic moment $(T)$ certainly does not create a complete spectral picture since simulation of space 
harmonics of magnetic field along the scope of the stator is lacking.

In simulation of engine run-up from inverter converter spectrum of harmonics of engine current (rotor and stator) during the run-up interval $\{0-0,1\}$ has been continuously changed and there was impression that they are insensitive to harmonics, that is, induction machine does not detect harmonics at the input of the machine. However, diagnostics based only on consideration of distribution in time domain at least creates initial conditions for correction of asymmetries and higher harmonics.

On diagrams at real proportion, which are obtained by simulation, harmonics that presents 0,1 part of the basic harmonic have been analyzed, since further reduction of values of harmonic amplitudes could cause serious problems, and therefore the value 0,1 in this case presents sufficient sensitivity for analysis of spectrum of harmonics in the induction machine.

Parallel active device for correction of harmonics should detect undesirable components of current produced in nonlinear loading such as induction machine, and inject the similar current (form of current) into the point where the correction device is. Corrector of asymmetries is ideal resource whose currents correspond to unwanted spectrum of components in the network current that should be annulled with as less loss as possible.

\section{References}

[1] Beaty, H. Motor require voltage limit-Elec. // World. 5, (1978), pp. 52-63.

[2] Vonina, D.; Nastran, J. Active Power Filter Compensating Harmonic Distortion and Unbalanced Non-Linear Loads. // Automatika. 3-4, (1998), pp. 111-118.

[3] Bjelić, S.; Marković, N.; Jakšić, U.; Živanić, J. Selection of linear filter elements parameters for measuring of voltage and currents components of direct and inverse order. // Przegląd Elektrotechniczny. R. 89 NR 1a/2013, (2013), pp. 172-176. http://pe.org.pl/articles/2013/1a/44.pdf

[4] Montsinger, V. M.; Cleam, J. E. Temperature limits for short time overloads, for oil-insulated neutral grunding reactors and transformers. // Tran. AIEE. 65, part II, (1986), pp. 966-973.

[5] Fuchs, E. F.; Poloujadof, M.; Neal, G. W. Starting performance of saturable three-phase induction motors. // IEEE Transactions on Energy Conversion. EC-3, 3, (1998), pp. 624-635.

[6] Bjelić, S.; Marković, N.; Jakšić, U. The simplified procedure for calculation of influence of thermal losses on decrease of technical endurance of electric equipment. // 3. Conference on Industrial Energy and Environmental Protection IEEP'11, Book of abstracts page. 28, (2011), 21$25 . \quad \mathrm{http}: / / \mathrm{www} . d r u s t v o-t e r m i c a r a . c o m /$ resources/ files/9981ff6.pdf

[7] MATLAB, Copyright 1984-2002, The Math Works, Version 6.5.0,180913a, June 2, 2000.

[8] Mohan, N.; Undeland, T. M.; Robbins, W. P. Power Electronics: Converters, Applications, and Design. John Wiley \& Sons, Inc., Section 8.4.1., NewYork, 1995.

[9] Marković, N.; Bjelić, S.; Jakšić, U.; Vujičić, M. Development of new measuring systems based on symmetric components in electric networks. // T120 electronics, Electronics and electrical engineering, ELEKTRONIKA IR ELEKTROTECHNIKA, Signal technology, Lithuania, 8(104), (2010), pp. 57-62. http://www.ee.ktu.lt/page.php?231
[10] Linders, J. R. Electric wave distorsion. Their hidden costs and containment. // IEEE Trans. Ind. Appl. 15, 5(1979), pp. 458-474. DOI: $10.1109 /$ TIA.1979.4503690

[11] Moran, L. A.; Fernandez L.; Dixon, J. W. Simple\&LowCost Strategy for Active Power Filters Connected in Cascade. // IEEE Trans. Ind. Elect., 44, 5(1997), pp. 621629. DOI: $10.1109 / 41.633456$

[12] Cardenas, V. M.; Vazquez, N. Analysis and Evaluation of Control Techniques for Active Power Filters: Sliding Mode Control and Proportional-Integral Control. // APEC '99. Fourteenth Annual Applied Power Electronics Conference, USA. 1, (2000), pp. 649-654.

[13] Kim, S.; Enjeti, P. N. Control Strategies for Active Power Filter in Three-Phase Four-Wire Systems. // Fifteenth Annual IEEE Applied Power Electronics Conference\&Exposition, APEC 2000, 1, Piscataway NJ, USA, (2000), pp. 420-426. DOI: 10.1109/APEC.2000.826137

[14] Bjelić, S. Energetic converters in networks and installations. SVEN Niš, 2007.

[15] Bjelić, S.; Jakšić, U.; Marković, N. Energetic converters. Kvark-Kraljevo, 2010

[16] Jeong, S. G.; Woo, M. H. DSP-Based Active Power Filter with Predictive Current Control. // IEEE Trans. Ind. Electron. 44, 3, (1997), pp. 329-336. http://serials.unibo.it/cgiser/start/it/spogli/df-s.tcl? prog_art $=641122$ \&language $=$ ITALIANO\&view $=$ articoli

[17] Aredes, M.; Hafner, J.; Heumann, K. A. Three-phase Fourwire Shunt Active Filter Using Six IGBTs. // EPE '95, 6th European Conference on Power Electronics and Applications, 1, Seville, Spain, (1995), pp. 874-879.

[18] Akagi, H.; Nabae, N.; Ato, S. Control Strategy of Active Power Filters Using Multiple Voltage Source PWM Converters. // IEEE Trans. Ind. Appl. 22, (1986), pp. 460465. DOI: $10.1109 /$ TIA.1986.4504743

[19] Aredes, M.; Watanabe, E. H. New Control Algorithms for Series and Shunt Three-phase Four-wire Active Power Filters. // IEEE Trans. Power Deliv. 10, 3, (1995), pp. 16491656.

[20] Verdelho, P.; Marques, G. D. An Active Power Filter and Unbalanced Current Compensator. // IEEE Trans. Ind. Electron. 44, 3, (1997), pp. 321-328.

[21] Dixon J.; Garcia, J. Control System for the Three--phase Active Power Filter which Simultaneously Compensates Power Factor and Unbalanced Loads. // IEEE Trans. Ind. Electron. 42, (1995), pp. 636-641. DOI: 10.1109/41.475504

\section{Authors' addresses}

\section{Nenad Marković, MSc}

Advanced Polytechnic School of Vocational Studies Uroševac, 24. Novembar, 38218 Leposavić, Srbija

E-mail: nen.mark74@yahoo.com

\section{Slobodan Bjelić, PhD}

Faculty of Technical Sciences Kosovska Mitrovica, University of Priština,

KnezaMiloša 7, 38220 Kosovska Mitrovica, Srbija

E-mail: slobodanbjelic49@yahoo.com

\section{Jeroslav Živanić, PhD}

Faculty of Technical Sciences Čačak,

University of Kragujevac,

Svetog Save 65, 32000 Čačak, Srbija

E-mail: jeroslav.zivanic@ftn.kg.ac.rs

\section{Uroš Jakšić, PhD}

Advanced Polytechnic School of Vocational Studies Zvečan Nušićeva 6, 38227 Zvečan, Srbija

E-mail: uros_jaksic@yahoo.com 